\title{
Biosimilars: Regulatory Status and Implications across the World
}

Rajesh Kumar $^{1 *}$, Sandra Sigala ${ }^{1}$, Renato Bertini Malgarini ${ }^{2}$, Giuseppe Pimpinella ${ }^{2}$, Luca Pani ${ }^{2}$, Sergio Pecorelli ${ }^{1,2}$ and Maurizio Memo

${ }^{1}$ Department of Molecular and Translational Medicine, University of Brescia - Health and Wealth, Viale Europa, 11, 25123 Brescia, Italy

2Italian Medicines Agency (AIFA), Rome, Italy

\begin{abstract}
Biological drugs, also known as first generation biopharmaceuticals, are being produced for the last 30 years and are in clinical use for a number of diseases. Recently, the expiry of many of these product patents led to the development of other non-innovator similar biologics at lower costs, having the same safety, purity and potency as their original counterparts. These non-innovator similar biologics are generally referred to as biosimilars.

Biosimilars are produced in living organisms by recombinant DNA techniques and exploiting the cellular mechanisms of the host so, there could be some differences at the molecular level due to their complex nature. Henceforth, they have to face numerous challenges for their development and approval, including the complex manufacturing process, immunogenicity issues, nomenclature, extrapolation of different indications, interchangeability with their originators, awareness amongst the clinicians and patients and the costs of production for the manufacturers.

As these molecules are designed to mimic human proteins, they can give rise to serious efficacy and safety concerns, indeed the standard generic approach is not applicable to demonstrate similarity between a biosimilar and its reference product. So, many Regulatory Authorities have established guidelines for the development and approval of biosimilars.

Biosimilars are an essential product category that makes biological drugs available to different markets at an affordable cost. Their use is ought to increase in the upcoming years as per the demand and supply of these drugs is concerned. Hence, aim of this review is to discuss the problems surrounding the biosimilars and to give an overview on their regulatory statuses across the world. Concluding, we believe that to achieve a balance between drug quality, safety and the population health needs, a profound knowledge of biosimilar development as well as joint effort of the manufacturers and their will to share the critical development data, is needed.
\end{abstract}

Keywords: Biosimilars; Biological drugs; Biosimilar regulations; Drug development; Similar biologics; Regulatory authorities

\section{Abbreviations}

recDNA: Recombinant DNA; G-CSF: Granulocyte-Colony Stimulating Factor; EPO: Erythropoietin; PRCA: Pure Red Cell Aplasia; rHuEPO: Recombinant Human Erythropoietin; EMA: European Medicine Agency; INN: International Nonproprietary Names; BPCI Act: Biologics Price Competition and Innovation Act; FDA: Food and Drug Administration; PK: Pharmacokinetics; PD: Pharmacodynamics; CMC: Chemistry Manufacturing And Control; PHS Act: Public Health Service Act; SEB: Subsequent Entry Biologic; EEA: European Economic Area; MoH: Ministry of Health; PMDA: Pharmaceuticals and Medical Devices Agency; KFDA: Korean Food and Drug Administration; MFDS: Ministry of Food and Drug Safety; CFDA: China Food and Drug Administration; CDSCO: Central Drug Standard Control Organization; HAS: Health Sciences Authority; ANVISA: Agência Nacional de Vigilância Sanitária; WHO: World Health Organization; PSUR: Periodic Safety Update Reports; TGA: Therapeutics Goods Administration

\section{Introduction}

Biological drugs are being produced for the last 30 years and are in clinical use for number of diseases: cancer, hepatitis, multiple sclerosis and anaemia, to cite few [1]. Biotechnological drugs are produced in living organisms by recombinant DNA (recDNA) techniques, exploiting physiological mechanisms of the host cells [2-4]. They usually are copies of human endogenous molecules, such as growth hormones, cytokines, insulin or erythropoietin. These products are also called first generation biopharmaceuticals.
Recently, the expiry (or near expiration) of patents of these biological drugs prompted the pharmaceutical industries and governing bodies to replace them with non-innovator similar biologic drugs. These products are a new class of drugs intended to be comparable in both safety and efficacy measures to the reference drug and are generally referred as biosimilars. The major purpose of this replacement is to reduce the costs of production and time of approval for market entry. Biosimilars are also known as similar biological products, followup biologics, second entry biological, subsequent entry biologics, biogenerics, multisource products and off-patent biotech products [5]

Generally, the termbiosimilar refers to a product which is biologically and functionally similar to the reference product, also called originator. By this definition, these drugs can be seen as comparable, but not identical to the reference product. These products cannot be deemed as a generic version of their originators, as they are not chemically derived single (small) molecular pharmaceutical entities, which are identical to the original drugs both in pharmaceutical equivalence (identical active substances) and bioequivalence (comparable pharmacokinetics) [6-

*Corresponding author: Rajesh Kumar, Department of Molecular and Translational Medicine, University of Brescia -Health and Wealth, Viale Europa, 11, 25123 Brescia, Italy, Tel: 0039 0303717653; Fax: 00390303717529 ; E-mail: rajck83@gmail.com

Received August 25, 2015; Accepted September 15, 2015; Published September 21,2015

Citation:KumarR, Sigala S, Malgarini RB, Pimpinella G, Pani L, etal.(2015)Biosimilars: Regulatory Status and Implications across the World. J Pharmacovigilance S3: 002. doi:10.4172/2329-6887.S3-002

Copyright: ( 2015 Kumar R, et al. This is an open-access article distributed unde the terms of the Creative Commons Attribution License, which permits unrestricted use, distribution, and reproduction in any medium, provided the original author and source are credited. 
12]. Moreover, in the case of generics, once the criteria of equivalence are established, these products can be waived from clinical efficacy and safety studies. For a biosimilar, the active substance is a protein, which is unlikely to be identical to its reference product, precisely because of their biological production mechanisms.

Nowadays, biosimilars represent new challenges not just in their production methods, but also in their efficacy and safety measures; it is, indeed, very difficult to avoid the heterogeneity between the same proteins from different manufactures or between the different batches for the product from the same manufacturer $[3,13]$.

Since the standard generic approach is not applicable to demonstrate similarity of biological/biotechnological derived products, the need for specific regulations arises for the registration, production and comparability of these products. It seems that the entire world is working towards a framework for developing and approving biosimilars, as demand grows for access to biological drugs at lower prices. That is why many countries are approaching towards the framework of biosimilar regulations (Figure 1). In this review, we are reporting the challenges (Table 1) that biosimilars have to face before entering the market and also the state of art on regulatory basis and complete list of biosimilars authorized in Nations with biosimilar regulations across the world.

\section{Challenges Faced by the Biosimilars}

\section{Manufacturing process}

Biologics are generally considered as drugs derived from organic sources or isolated from living organisms, such as yeast, bacteria and mammalian cell lines. Usually, specific genetically modified vectors are used to produce the end-product through various steps, including the appropriate genetic sequence, selection of vector, suitable cell expression systems, quality control and purification systems. All these factors can deeply influence the structure of the biological product. Moreover, even the basic parameters like $\mathrm{pH}$, temperature or tools used for storage and packaging can influence the final structure of the end-product [6]. For example, the glycosylation pattern of granulocytecolony stimulating factor (G-CSF) [7] and interferon- $\gamma$ [8] can be different in different expression systems. Another example is EPO (erythropoietin), a molecule which gave immunogenicity issues, in some cases, due to the minor changes in the manufacturing process of the final product, although this safety issue concerns an originator [9$12,14]$. Thus, small changes in the manufacturing process may change the product's characteristics, with a drastic impact on clinical outcome.

Normally, it is not advisable to bring any changes to the manufacturing process of biosimilars compared to their original counterpart. However, the changes are somehow inevitable as the manufacturing data for the reference product is not accessible for the biosimilar manufacturers, as it is property of the innovator manufacturer, even after the patent expiry [15]. Moreover, modifications can also be made to improve the quality, efficiency and reliability of the manufacturing process or the end-product per se. These changes may lead to structural differences, resulting in efficacy modifications and with potential insurgence of adverse effects, i.e., immunogenicity. In these cases, further non-clinical and clinical evaluations might be needed to evaluate the product, depending on the extent of modifications brought $[16,17]$.

\section{Extrapolation of different indications}

The extrapolation across indications is a concept pointing that, when the clinical data for a biological drug is generated for one therapeutical indication, they can be extrapolated to other indications, taking into account, for the drug efficacy and safety, of the overall information gained from the comparability exercise.

In the context of biosimilars, extrapolation from one indication to another may be considered if biosimilarity to the reference product has a comprehensive comparability, including efficacy, safety and immunogenicity, suitable to detect clinically relevant differences, in particular if the mechanism of action of the active substance and the target receptor(s) is the same. In Europe, this concept has been successfully implemented with biosimilars of EPO, filgrastim and infliximab.

\section{Immunogenicity}

The primary safety concern for biosimilars is their potential to induce immune response [18], especially when administered as multiple doses over longtime periods $[19,20]$. One commonly cited example for immunogenicity of biotechnological drugs (both reference products and biosimilars) is EPO. In this case, neutralizing naturally anti-EPO antibodies produced by patient's immunological system resulted in a rare condition known as Ab-mediated pure red cell aplasia (PRCA), that usually occurs in patients with anaemia due to chronic kidney disease and treated with EPO [9-12]. The PRCA cases were associated with a breakdown of immune tolerance to treatment with rhEPO, particularly with subcutaneous administration, resulting in neutralizing $\mathrm{Ab}$ formation against both recombinant and endogenous EPO [21]. It should be underlined, however, that, beside the biotechnological product involved, it is important to consider other factors that can be potentially immunogenic, such as the variation in the glycosylation pattern, denaturation or aggregation, the presence of impurities in the solution, dose, route of administration, treatment duration and genetic characteristics of patients [22]. Hence, the immunogenicity of a biosimilar must always be deeply investigated.

\section{Post-marketing surveillance (Pharmacovigilance)}

Although drugs are marketed only after fulfilling requests of the Regulatory Authority for their quality, efficacy and safety, the long

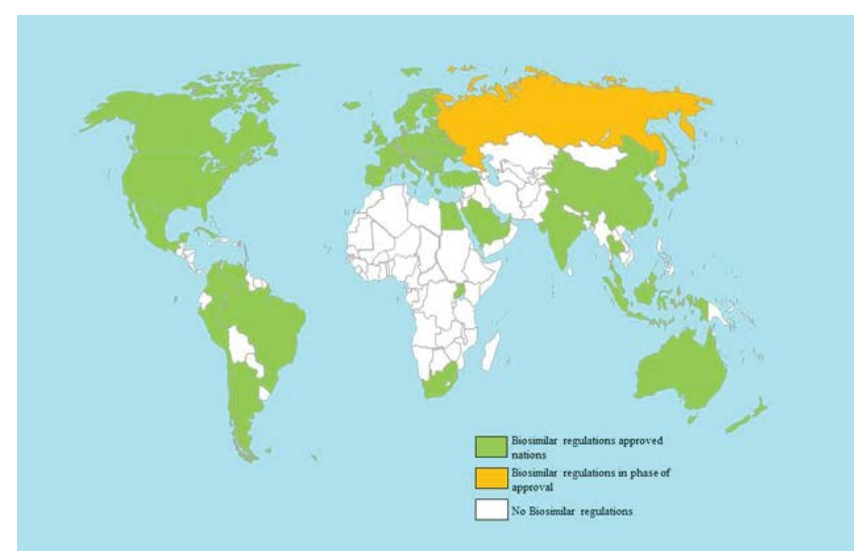

Figure 1: World map showing Countries that nowadays have biosimila guidelines (green) which includes USA, Canada, Europe (including Iceland, Sweden and Norway), India, Australia, Japan, South Korea, Republic of South Africa, China, Brazil, Mexico, Argentina, Peru, Colombia, Venezuela, Chile, Cuba, Singapore, Malaysia, Thailand, Saudi Arabia, Egypt, Uganda, Turkey; countries which are on the verge of publishing their biosimilar guidelines (orange) Russia; and countries which do not have any biosimilar guidelines (white). 


\begin{tabular}{|c|c|}
\hline Challenge & Description \\
\hline Manufacturing Process & $\begin{array}{l}\text { Use of specific genetically modified vectors to produce the end product in biological settings by going through various steps: } \\
\text { Use of appropriate genetic sequence } \\
\text { Selection of vectors } \\
\text { Selection of suitable cell expression systems } \\
\text { Quality control and purification systems } \\
\text { - } \\
\text { Rigorous control of temperature and pH. } \\
\text { Use of suitable storage and packaging materials }\end{array}$ \\
\hline Immunogenicity & $\begin{array}{l}\text { Due to the nature of these products which are similar to human proteins, so potentially can induce immune responses due to: } \\
\text { The impurities accumulated in the development processes } \\
\text { Variation in amino acid sequences } \\
\text { Post translational modifications like denaturation, aggregation or glycosylation patterns }\end{array}$ \\
\hline Naming issues & $\begin{array}{l}\text { The product information and the manufacturing company and site should be recognized through the name, in case it produces } \\
\text { any adverse effects }\end{array}$ \\
\hline Extrapolation of different indications & $\begin{array}{l}\text { Difficulty in extrapolating the other indications for which a biosimilar product has not undergone any clinical evaluation even } \\
\text { though the originator has demonstrated its worth in terms of safety and efficacy }\end{array}$ \\
\hline Post-marketing surveillance & Important as long term consumption data and the increase in number of test subjects can reveal serious adverse effects \\
\hline Interchangeability & $\begin{array}{l}\text { Difficult as these are not generic drugs but biological copies of the existing molecules which can be different in molecular } \\
\text { structure due to their complex nature. }\end{array}$ \\
\hline $\begin{array}{l}\text { Cost effectiveness and harmonization of } \\
\text { clinical trials }\end{array}$ & $\begin{array}{l}\text { Difficulty in cutting the cost of production due to the lack in harmonization of comparability process. The comparability studies } \\
\text { are often done individually for the Countries and not worldwide and also using only the comparator which is authorized in the } \\
\text { same Country. }\end{array}$ \\
\hline Awareness & Important to impart knowledge, to both clinicians and patients involved, about the biosimilar products and their complex nature. \\
\hline
\end{tabular}

Table 1: Challenges faced by the biosimilars.

term consumption data in a large population, new findings and pharmaceutical progress can reveal adverse effects that were not previously seen during the development. This is true as a general concept, but, in particular for biosimilars, manufacturers need to plan an extended post-market surveillance, that is very important to grab the immunogenic phenomenon, as well as efficacy in the different diseases $[23,24]$. The biosimilar guidelines state that the pharmacovigilance plan should be included in the data submitted for the registration of a biosimilar.

\section{Interchangeability issues}

Establishing interchangeability is a vital step towards the complete acceptance of biosimilars. The products that are approved for the same indication can be considered interchangeable and used for the said indication. This is not to be confused with the term substitutable, which refers to the product that can be used in lieu of another during the same therapeutical treatment.

Generic drugs are usually considered therapeutically equivalent with their reference products [25]. In these cases, substitution is permitted. As already underlined, biotechnological drugs are distinct from chemical drugs and it's difficult that two biologic drugs could be exactly the same. It is widely agreed by a broad consensus of the scientific, regulatory and industry communities, that biotechnological drugs have the potential to present unique risks when switched, without involving the prescribing physician. Consequently, they should not be substituted without prescription. Therefore, issues such as immunogenicity, efficacy, safety and clearance could restrict the Regulatory Authorities from accepting biosimilars as interchangeable. The US is the only Country that formally allows an interchangeable designation for biological drugs. While European Medicines Agency (EMA) states that the biosimilar interchangeability should be handled by each Nation on its own and Health Canada left this to the physician discretion. Other Nations are also moving towards this direction as, by the time this review was written; no specific adverse effects were seen applying the interchangeable biosimilar approach. Indeed, a number of studies showed that switching between various EPO is safe and does not lead to an increase in adverse events [26-28]. Nevertheless, extensive pharmacovigilance studies, risk management plans and awareness amongst patients and physicians about the nature of biosimilars and their manufacturing process are needed to gather strong real world evidence data to prove comparability between a biosimilar and its reference product.

\section{Nomenclature}

In order to be globally recognized by a unique name, the International Nonproprietary Names (INN) has been assigned to biological products for the last 5-6 decades. Products are named in relation to their structure or function and product-specific letter groups, called stems, helping health professionals to easily recognize the compound. For example, the stem for EPO molecule is -poietin, while for synthetic polypeptides with a corticotrophin-like action is -actide. However, protein structures are increasing in complexity and also the manufacturing processes may make these molecules structurally, biologically or even immunologically different from the natural proteins. So, the INN naming for biosimilars is a topic of increasing complexity $[29,30]$. Indeed, some Regulatory Authorities use the INN whereas others consider a distinct nonproprietary identifier for biosimilars: for example, Australia and Japan add a qualifier that is usually short and separate and sometimes it can incorporate the name of manufacturing company.

To avoid proliferation of separate and distinct national qualifiers systems, recently WHO has proposed the Biological Qualifier Scheme, applicable prospectively and retrospectively to all biological substances assigned INN's, which can be adopted on a voluntary basis by any Regulatory Authority. This scheme will assign a code of four letters at random to complement the INN for a biological compound and it will uniquely identify directly or indirectly the manufacturer and manufacturing site of the active substance in a biological product [31].

\section{Awareness amongst the clinicians and patients}

The paradigm that biosimilars are "similar but not identical" often leaves questions on their efficacy and safety. Since the active substance of a biosimilar is not identical to the active substance of the reference product, the regulatory requirements for approval of generics are inadequate to demonstrate the quality, efficacy, and safety of biosimilars [32]. 
The clinicians often look at clinical data to determine the efficacy and safety of a drug. For biosimilars, in some cases, the clinical data can be reduced, if the comparison of structural and functional characteristics is comprehensive. Moreover, in some Countries, problems have been reported on biological drugs which are erroneously called biosimilars, due to the inconsistent use of the terminology [29]. Sometimes, clinicians are just not well informed about the scientific concept regarding the development and licensing of biosimilars. This can lead to the fear of their use for some of proposed indications, especially for those for which no specific clinical trials have been performed, but data are extrapolated based on the efficacy and safety for other indications.

\section{Costs, time and harmonization}

Biosimilars can lead to significant cost reductions, not only for the final recipients, but also for those Governing Authorities who have reimbursement policies for the pharmaceuticals. This can provide relocation of the savings coming from biosimilar use.

However, each Regulatory Authority has its own guidelines for the comparability of biosimilar to its reference product. These differences make hard for the manufacturing companies to reduce the productive costs of these products, as they may have to establish different comparison in different Countries. Moreover, the biosimilars have to follow particular development pattern which significantly raises the costs and timing of production. The development of biosimilars takes 8 to 10 years and costs between $\$ 100$ million to $\$ 200$ million, in contrast to generics, that takes 3 to 5 years and costs $\$ 1$ million to $\$ 5$ million $[33,34]$. To reduce the costs of production, one suggestion is to harmonize the clinical trials and comparability studies not for single market but at an international level.

\section{Biosimilar Regulatory Scenario across the World}

\section{Europe}

EU including Norway, Iceland and Sweden: In the European Union (EU), EMA was the first competent Authority that issued a legal framework for approving biosimilars in 2004 [35]. Recently, EMA has revised these guidelines, which are effective from $30^{\text {th }}$ April 2015. In these guidelines, unlike generics, EMA establishes that biosimilars can be approved only at the central level and not at the single Nation level.

According to the EMA guidelines, "A biosimilar is a biological medicinal product that contains a version of the active substance of an already authorized original biological medicinal product (reference medicinal product) in the EEA and it should establish the similarity to the reference medicinal product in terms of quality characteristics, biological activity, safety and efficacy based on a comprehensive comparability." In order to generate coherent data and conclusions during the development of a biosimilar, a single reference product, which is authorized by EMA, should be used as the comparator throughout the comparability programme. However, in certain clinical and in in vivo non-clinical studies, to facilitate the global development of biosimilars and to avoid unnecessary repetition of clinical trials, sponsors can also use a reference product authorized outside Europe [36]. Though, this non-European comparator should be authorized by a Regulatory Authority with similar scientific and regulatory standards as EMA and the before applicant needs to demonstrate that it is representative of the EMA-authorized reference product. These guiding principles are established to ensure the similarity between the biosimilar and the reference product and to guarantee that the previously proven efficacy and safety of the reference product also apply to the biosimilar. A biosimilar should be highly similar to the reference product in physiochemical and biological terms and any differences with regard to its efficacy and safety should be duly justified.

Both FDA and EMA approve the stepwise approach throughout the development program for a biosimilar, to reduce the extent and nature of non-clinical in vivo studies and clinical studies, but evidence obtained in the previous step(s) including the physiochemical, biological and non-clinical in vitro data need to be robust from both the scientific and statistical points of view. Furthermore, EMA guideline states that in certain specific circumstances, a confirmatory clinical trial may not be necessary if the similar efficacy and safety can clearly be deduced for the other indications, based on the earlier steps and clinical data obtained for one indication, between biosimilar and the reference product. It also affirms that the aim of clinical studies, generally, is to address the slight differences shown at the previous steps, hence, it cannot be used to justify substantial differences in quality attributes of the biosimilar products. If the comparability indicates relevant differences, then a stand-alone development to support a full marketing authorization application should be considered instead. However, EMA claims that these simplified approaches need to be discussed with Regulatory Authorities and that the impurity profile and nature of excipients of a biosimilar should not give rise to any immunologic concerns [35]. It also includes the terminology for biosimilars, the principles of biosimilarity and the requirements regarding the posology, route of administration and formulation of biosimilars.

Other than this EMA's overarching biosimilar guideline, there are two additional guideline documents:

Guideline addressing the quality issues related to biosimilar development (effective from December 2014) [35].

Guideline on the clinical and non-clinical aspects related to biosimilar development (effective from July 2015) [37,38].

Finally, EMA gives specific guidelines for biosimilars of EPO, G-CSF, monoclonal antibodies, insulin products and vaccines.

Since the publication of biosimilar guidelines in 2004, EMA has approved 21 biosimilars (Table 2) including 5 different types of EPO, 7 filgrastim, 2 follitropin alpha, 2 infliximab, 1 insulin glargine and 2 somatropins. Two of these were, later, withdrawn from the market (filgrastim in April 2011 and somatropin in May 2012).

Russia: Russian law allows the registration of biological drugs defined as medicinal products containing a biological active substance. A biological active substance is a substance that is produced by or extracted from a biological source and requires physical, chemical and biological testing, characterization of its quality, along with its production process and control. It does not define a biosimiliar, nor it provides a regulatory framework for the biosimilar approval; this implies that a full clinical developmental program, similar to the innovator biological product, must be completed even for a biosimilar. An applicant must submit a registration dossier to the Ministry of Health $(\mathrm{MoH})$, the regulatory body for drugs evaluation, with its affiliation Federal State Budgetary Institution - Scientific Centre for Expert Evaluation of Medicinal Products (FSBI-SCEMP). The complete dossier in Russian must be submitted to the $\mathrm{MoH}$, and should include administrative documents, description of pharmaceutical properties and data about the manufacturing process, quality control, preclinical studies (pharmacological and toxicological) and clinical studies regarding the biological drug. Russia follows the European Guidelines for biosimilars for data requirements for the registration of a biological drug [39]. 
Citation: Kumar R, Sigala S, Malgarini RB, Pimpinella G, Pani L, et al. (2015) Biosimilars: Regulatory Status and Implications across the World. J Pharmacovigilance S3: 002. doi:10.4172/2329-6887.S3-002

Page 5 of 14

\begin{tabular}{|c|c|c|c|c|}
\hline Brand name & Reference product & Indicated for & Manufacturer & Authorization date \\
\hline Abseamed & \multirow[t]{3}{*}{ epoetin alfa } & \multirow{2}{*}{$\begin{array}{c}\text { Anaemia, } \\
\text { Cancer, } \\
\text { Chronic kidney failure }\end{array}$} & $\begin{array}{c}\text { Medice- } \\
\text { ArzneimittelPütter }\end{array}$ & 28 Aug 2007 \\
\hline Epoetin alfa Hexal & & & Hexal & 28 Aug 2007 \\
\hline Binocrit & & $\begin{array}{c}\text { Anaemia, } \\
\text { Chronickidneyfailure }\end{array}$ & Sandoz & 28 Aug 2007 \\
\hline Retacrit & \multirow[t]{2}{*}{ epoetin zeta } & \multirow{2}{*}{$\begin{array}{c}\text { Anaemia, } \\
\text { Autologous blood transfusion, } \\
\text { Cancer, } \\
\text { Chronic kidney failure }\end{array}$} & Hospira & 18 Dec 2007 \\
\hline Silapo & & & STADA $R$ and D & 18 Dec 2007 \\
\hline Accofil & \multirow[t]{2}{*}{ filgrastim } & \multirow[t]{2}{*}{ Neutropenia } & Accord Healthcare & 18 Sep 2014 \\
\hline Ratiograstim & & & Ratiopharm & 15 Sep 2008 \\
\hline Biograstim & \multirow[t]{7}{*}{ filgrastim } & \multirow{7}{*}{$\begin{array}{c}\text { Cancer, } \\
\text { Haematopoietic stem cell } \\
\text { transplantation, } \\
\text { Neutropenia }\end{array}$} & CT Arzneimittel & 15 Sep 2008 \\
\hline Filgrastim Hexal & & & Hexal & 6 Feb 2009 \\
\hline Filgrastim ratiopharm & & & Ratiopharm & $\begin{array}{c}15 \text { Sep } 2008 \\
\text { Withdrawn on } 20 \text { Apr } 2011\end{array}$ \\
\hline Grastofil & & & Apotex & 18 Oct 2013 \\
\hline Nivestim & & & Hospira & 8 Jun 2010 \\
\hline Tevagrastim & & & TevaGenerics & 15 Sep 2008 \\
\hline Zarzio & & & Sandoz & 6 Feb 2009 \\
\hline Bemfola & \multirow[t]{2}{*}{ follitropin alfa } & \multirow[t]{2}{*}{ Anovulation (IVF) } & Finox Biotech & 24 Mar2014 \\
\hline Ovaleap & & & TevaPharma & 27 Sep 2013 \\
\hline Inflectra & \multirow[t]{2}{*}{ Infliximab } & \multirow[b]{2}{*}{$\begin{array}{l}\text { Ankylosing spondylitis, } \\
\text { Crohn's disease, } \\
\text { Psoriatic arthritis, } \\
\text { Psoriasis, } \\
\text { Rheumatoid arthritis, } \\
\text { Ulcerative colitis }\end{array}$} & Hospira & 10 Sep 2013 \\
\hline Remsima & & & Celltrion & 10 Sep 2013 \\
\hline Abasaglar (previously Abasria) & $\begin{array}{l}\text { Insulin } \\
\text { glargine }\end{array}$ & Diabetes & Eli Lilly/ Boehringer Ingelheim & 9 Sep 2014 \\
\hline Omnitrope & \multirow[t]{2}{*}{ somatropin } & \multirow{2}{*}{$\begin{array}{l}\text { Pituitary dwarfism, } \\
\text { Prader-Willi syndrome, } \\
\text { Turner syndrome }\end{array}$} & Sandoz & 12 Apr 2006 \\
\hline Valtropin & & & BioPartners & $\begin{array}{l}\qquad 24 \text { Apr } 2006 \\
\text { Withdrawn on } 10 \text { May } 2012\end{array}$ \\
\hline
\end{tabular}

Source: European Medicine Agency and Gabi Journal.

Table 2: EMA approved biosimilars.

Nevertheless, the guidelines for biosimilars in Russia are under development. In particular, two draft guidelines have been prepared: one by the medical community and one by the pharmaceutical industry. This regulatory guidance will probably be enacted by the end of 2015 or by the first half of 2016 [40].

Russia has an enormous market for biological drugs, including biosimilars. In fact, many biosimilars have been granted authorization even though they don't have any particular guidelines about similar biological products. These products include EPO (20 different products), interferons (53 different products), monoclonal antibodies (42 different products), insulin (61 different products), somatropins (11 different products), G-CSF (24 different products), heparins (55 different products), plasma coagulation factors (31 different products), r-coagulation factors (9 different products) [41]. The last biosimilar authorized in Russian market was Biocad's Acellbia, a non-originator of rituximab, in April 2014.

\section{North America}

USA: The submission of a marketing application for a proposed therapeutic product as a biosimilar of a reference product is done under the section 351(k) of the Public Health Service Act (PHS Act) [42].The recent changes after the Biologics Price Competition and Innovation Act (BPCI Act) [43] amended the PHS Act and other statutes to create an abbreviated licensure pathway for biological products that are demonstrated to be "biosimilar" or "interchangeable" with an FDAlicensed biological product, as stated in the Patient Protection and Affordable Care Act (Affordable Care Act) [44] signed into law on
March 23, 2010.

Following these changes, FDA published three draft guidelines in 2012, which were finalized on $28^{\text {th }}$ April 2015. These guidelines provide robust details on scientific and quality considerations, as well as questions and answers on biosimilars listed as follows:

- Scientific considerations in demonstrating biosimilarity to a reference product [31]

- Quality considerations in demonstrating biosimilarity of a therapeutic protein product to a reference product [45]

- Biosimilars: Questions and answers regarding implementation of the Biologics Price Competition and Innovation Act of 2009 [46].

The guidance on scientific considerations is the key guidance to be taken into account by the sponsors, to determine biosimilarity and discusses important scientific considerations. Briefly, it describes the stepwise approach, which includes a comparison of proposed product and the reference product with respect to structure, function, animal toxicity, human PK and PD, clinical immunogenicity and clinical efficacy and safety. It also takes into account the risk-based totalityof-the-evidence approach (considerations of both the quantity and quality of the evidence to support effectiveness for drugs and biological products, to reduce the residual uncertainties in comparative studies) and general scientific principles in conducting comparative studies, that include analytical studies, at least one clinical PK study and, if appropriate, at least one PD study. 
The second guidance outlines the quality, i.e., chemistry, manufacturing and control (CMC) considerations that the sponsors need to take into account when determining biosimilarity, especially the use of analytical methodology that needs to demonstrate adequate sensitivity and specificity to detect and characterize differences between the proposed and the reference products.

The Question and answer guidance responds to questions commonly asked by industry, and includes issues such as exclusivity, biosimilarity and interchangeability.

According to the USA guidelines, a biosimilar is defined as "the biological product highly similar to the reference product notwithstanding minor differences in clinically inactive components," and that "there are no clinically meaningful differences between the biological product and the reference product in terms of the safety, purity, and potency of the product." Biological product is "a virus, therapeutic serum, toxin, antitoxin, vaccine, blood, blood component or derivative, allergenic product, protein (except any chemically synthesized polypeptide), or analogous, or arsphenamine or derivative of arsphenamine (or any other trivalent organic arsenic compound), applicable to the prevention, treatment, or cure of a disease or condition of human beings." The reference product is considered as "the single biological product licensed under section 351(a) of the PHS Act against which a biological product is evaluated in a $351(\mathrm{k})$ application." [31,47].

From the interchangeability point of view, a sponsor must demonstrate that the biosimilar are expected to produce the same clinical results as the reference product in any given patient. For a biological product that is administered more than once, the risk of alternating or switching between use of the biosimilar and the reference product is not greater than the risk of maintaining the patient on the reference product [48].

Other FDA draft guidelines relevant for the biosimilars are:

- Clinical pharmacology data, to support a demonstration of biosimilarity to a reference product, released in May 2014 [49]

- Formal meetings between FDA and biosimilar sponsors, released in March 2013 [50]

- Reference product exclusivity, released in August 2014 [51]. If, the non-US authorized reference product is used then a three way bridged comparative study should be done between proposed biosimilar, US-authorized similar reference product and non-US authorized reference product, to sustain the biosimilarity.

Up to now, the first and only biosimilar approved by FDA is Zarxio (filgrastim-sndz) injection on $6^{\text {th }}$ March 2015 [52], for all the five indications for which US-licensed reference product Neupogen is approved.

Approved by the BPCI Act, FDA can designate a biosimilar as interchangeable with its reference product. However, Zarxio was approved as a biosimilar and not as an interchangeable product. So, it cannot substitute the reference product without the intervention of the physician who prescribed the reference product. FDA also designated a non-proprietary name to this product (filgrastim-sndz), in view of Agency's decision to issue draft guidance on a comprehensive naming policy for biosimilars in near future. Moreover, in September 2014, FDA has launched the purple book (equivalent of "Orange book" listing the pharmaceuticals and generic equivalents), which lists the biologicals and interchangeable biosimilars licensed in US. It contains the information about date of licensure of the reference product, the date of first licensure from which exclusivity of that product is calculated and also the reference product exclusivity expiry date. The date of first licensure is important for the biosimilar manufacturers for filling an application for biosimilar, as it is stated in the guidance that the biological originator will acquire marketing exclusivity for a period of 12 years from the afore-mentioned date $[52,53]$.

Canada: The before Biologics and Genetic Therapies Directorate (BGTD) of Health Canada is responsible for applying the Food and Drug regulations, to ensure that the drugs defined by Schedule $C$ and Schedule D (for biologics or biosimilars) of Food and Drugs Act are safe, effective and of high quality for human use in Canada.

On $5^{\text {th }}$ March 2010, Health Canada issued the guidelines for biosimilars, designated as Subsequent Entry Biologics (SEBs), in the document entitled "Guidance for Sponsors: Information and Submission Requirements for Subsequent Entry Biologics (SEBs)". These documents were later complemented by other accompanying guidance:

- Publication of Updates to Guidance Document: Data Protection under C.08.004.1 of the Food and Drug Regulations (8 March 2010)" [54]

- Publication of Updates to Guidance Document: Patented Medicines (Notice of Compliance) Regulations (8 March 2010) [55]

- Questions and Answers to Accompany the Final Guidance for Sponsors: Information and Submission Requirements for Subsequent Entry Biologics (SEBs) (27 May 2010) [56].

These documents define the Biologic drug (Médicament biologique) and Subsequent Entry Biologics (SEBs) (Produit biologique ultérieur $(\mathrm{PBU}))$. Biologic drug is the one derived through the metabolic activity of living organism and tend to be significantly variable and structurally complex than chemically synthesized drugs. SEBs is biologic drugs that enter the market subsequent to a version previously authorized in Canada, and with demonstrated similarity to a reference product. A SEB relies in part on prior information regarding efficacy and safety that is deemed relevant, due to the demonstration of similarity to the reference product, that influences the amount and type of original data required [57]. The extrapolation of indications for SEBs is very carefully considered, based on a set of principles such as similarity that must be demonstrated by comprehensive comparative characterization. Indeed, there should not be any differences in

- The active ingredients with an impact on mechanism of action,

- The pathophysiological mechanisms or clinical experiences or the mechanisms of action for each use when compared to the reference drug

- The route of administration, posology and $\mathrm{PK} / \mathrm{PD}$ profiles [58].

To date there are three SEBs approved by Health Canada: one somatropin product (Omnitrope in April 2009) and 2 infliximab products (Inflectra and Remsima in January 2014). In Europe, Inflectra and Remsina are also approved for Crohn's disease but due to some differences with the respective reference products, extrapolation to these indications were not recommended in Canada.

Mexico: The regulatory body for approval of medicines, the Federal Commission for the Protection against Sanitary Risks (COFEPRIS), reformed the legal framework for biosimilars on $19^{\text {th }}$ October 2011, in 
Mexican government's official journal (Diaro Oficial de la Federación), which came into effect on $20^{\text {th }}$ April 2012. Before that, approval criteria for generics were used as the basis for biosimilar authorization, being the reason for the approval of 23 biosimilars registered in Mexico. Due to the lack of the adequate pharmacovigilance, no post-marketing data on these drugs are available [59]. However, according to new guidelines issued by COFEPRIS on $9^{\text {th }}$ February 2015, these previously licensed drugs must be renewed every five years. Therefore, these drugs will have to undergo the current legislation and demonstrate biosimilarity regarding physicochemical, preclinical/clinical studies, pharmacovigilance and immunogenicity data. These guidelines refer to non-originator drugs as biocomparables and do not define the nature and amount of studies necessary for their approval $[60,61]$.

\section{Asia}

Japan: The main regulatory and decision making body for the scientific evaluation and approval of medicines in Japan is the Ministry for Health Labour and Welfare (MHLW). The other regulatory Agency that conducts scientific reviews of marketing authorization application and post marketing issues, including adverse drug reactions of biological products, is the Pharmaceuticals and Medical Devices Agency (PMDA).

Japanese guidelines for biosimilars are based on the EMA guidelines and were issued on $4^{\text {th }}$ March 2009. These guidelines refer to biosimilars as "follow-on biologics" which are defined as "a biotechnological drug product developed to be comparable in regard to quality, safety and efficacy to an already approved biotechnology-derived product of a different company". The "comparability" should be highly similar and guidelines state that the existing knowledge should be sufficiently predictive to ensure that any differences in quality attributes, including the manufacturing process, would have no adverse impact on the drug product or on its efficacy and safety. Moreover, the comparability should be demonstrated through both non-clinical and clinical studies. The clinical studies should be conducted in a step-wise approach (PK and PD studies, clinical efficacy and safety studies), since the scope of clinical studies necessary will vary according to the available information at previous steps (which is in accordance with both EMA and FDA guidelines). Furthermore, the reference product should be already approved in Japan and it should be used throughout the entire development period of the biosimilar. However, if non-Japanesesourced reference product should be used in comparability exercise, it is required to explain that it is the representative of the Japanese sourced reference product by analytical assays and other available information. The dose form and administration route of a biosimilar should be the same as that of reference product, but the formulation can be different, as long as there are no adverse effects on efficacy and safety. At last, a robust post-marketing surveillance study and risk management plan should be designed for an appropriate time after the approval of biosimilars [62].

Currently, PMDA has approved seven biosimilars: 3 for filgrastim and 1 each for EPO, infliximab, insulin and somatropin (supplementary Table 1).

South Korea: South Korean Ministry of Food and Drug Safety (MFDS), formerly the Korean Food and Drug Administration (KFDA) in July 2009 issued the guidelines for biosimilars through its Agency, the Biopharmaceuticals and Herbal Medicines Bureau (BHMB), which is responsible for the scientific evaluation of medicines developed by pharmaceutical companies for use in the South Korea.
The MFDS guideline takes its backbone from the European, Japanese and WHO guidelines. It covers general considerations for biosimilar approval, selection of reference drugs, data requirements for authorization, quality, non-clinical and clinical testing of biosimilars and well-characterized recombinant protein products. These guidelines define in details all the methodologies and requirements that need to be taken into consideration while applying for a biosimilar approval. They are also specific for the type of biosimilar (such as G-CSF molecules, EPO, monoclonal antibodies, vaccines), but can also be applied to all the biologicals in general.

According to the MFDS guideline, "a biosimilar is defined as a biological product that is comparable to an already marketed reference product in terms of quality, safety and efficacy". The reference drug used to demonstrate the comparability of a biosimilar through quality, non-clinical and clinical studies should already be licensed in Korea and, under certain circumstances, a product which is same as the biological product already present in Korea, can also be used as a reference product. The reference product also lays the basis for biosimilar dose, form and route of administration.

If the biosimilar comparability data are comprehensive on the characterization and quality comparison, it's possible to reduce the amount of non-clinical and clinical data. In some cases, if efficacy and safety of a biosimilar for a particular clinical indication have been demonstrated to be similar to the reference drug, then the biosimilar product may get the extrapolation also for other indications, as it occurs in other Nations [63]. MFDS has authorized 4 biosimilars since 2012, one each for etanercept, infliximab, somatropin and trastuzumab (supplementary Table 1) [64].

China: On 28 $8^{\text {th }}$ February 2015, the Chinese Food and Drug Administration (CFDA) released the Country's first biosimilar guidelines based on the draft guidance issued on $29^{\text {th }}$ October 2014 by China's Center for Drug Evaluation (CDE) [65-70], which outline the principles for research, development and evaluation of biosimilars, methods for the use of reference products, pharmaceutical, nonclinical, clinical studies and their evaluations, product specifications and pharmacovigilance.

The biosimilar draft aligns with guidelines of EMA and FDA and it also signals the interest of the CFDA to develop biolosimilars that are on par with western standards.

According to China guidelines, biosimilar is defined as "a similar biotherapeutic product (SBP) that is similar in quality, safety and efficacy and should have the same amino acid sequence as the originator". An already CFDA-approved originator should be used as the reference product. A CFDA-approved biosimilar cannot itself be used as a reference product. It also states that all the SBP's should be treated as a new drug, hence, they have to follow the registration process for a new drug, which can take up to 4-6 years, but all the technical issues regarding the comparability should follow processes defined in the guidelines. Furthermore, pharmaceutical companies, in their applications, should state that the submitted drug is to be reviewed as biosimilar [66,67].

Moreover, guidelines lay some basic principles for the research, development and evaluation of recombinant therapeutic products. First, it states the comparability principle for the biosimilar at each developmental stage against the reference product. Second, the principle of stepwise development, i.e. first analytical then non-clinical and then clinical studies should be conducted. Third, requirements for renouncement or reduction of testing need to be based on the results 
of earlier stage testing. For example, if comparative quality studies show only small differences between the biosimilar and the reference product, nonclinical data may be limited to comparative PK, PD and immunogenicity studies. If differences or uncertainty regarding similarity are still present, comparative clinical safety and efficacy trials must be conducted. On the other hand, when these comparative studies show no or little differences or uncertainty regarding similarity, further comparative clinical efficacy and safety trials can be waived. The SBP Guidance also includes very brief and general sections on package insert and pharmacovigilance. The package insert should be the same, including indications, dosage form, strength, and safety information as the reference product, except when the biosimilar is approved for fewer indications. The pharmacovigilance section requires that applicants submit a post market risk management plan [68-70]. The CFDA also states that pharmaceutical companies should consider carefully the development of other categories such as polyethylene glycol-modified products and antibody-coupled drugs as biosimilars.

Furthermore, the Biotechnology Industry Organization (BIO) and the R\&D-based Pharmaceutical Association in China (RDPAC) both asked the CFDA, if discrepancies are observed at the CMC level or the preclinical level, that the candidate product should not be considered as a biosimilar and it should be allowed to switch to new drug development and registration pathway directly [65].

The Country has approved 382 genetically engineered drugs and genetically engineered vaccines, but only 21 products are innovative, while the rest are biosimilars, according to SMEI data. The first recombinant human interferon 1 beta was launched in 1989. EPO, G-CSF, insulins and monoclonal antibodies are also commercialized in China [71].

India: The main regulating act for the new drugs in India is the Drugs and Cosmetics Act, active from 1940. This act regulates all the import, manufacture, sale and distribution of drugs, biologicals, cosmetics, medical devices and animal health products.

The major governing body for the biosimilars in India is the Ministry of Health and Family Welfare, which comprises the Central Drug Standard Control Organization (CDSCO) and Drug Controller General India (DCGI). These organizations also take expert advice from two different bodies for the biologics, i.e., Review Committee on Genetic (RCGM) and Genetic Engineering Approval Committee (GEAC). All these bodies regulate the procedures for new drugs, imported drugs and clinical trials. Due to the federal nature of States in India, the manufacturing license is given by each State Authority.

India is home to about 10000 pharmaceutical manufacturers, as local manufacture has regulatory advantage over import products. It is a very price-sensitive market, as Government does not refund any costs regarding medicines. A huge amount of generics are available, called branded generics, as the products are not innovators, but they have brand names associated [72].

India has two different regulatory approaches, depending if the drug is locally manufactured or imported. For the imported drug, there is a three-step process: new drug approval, registration of the site where the drug is manufactured and import license obtainment. All these three steps are granted and regulated by the National Authority, i.e., CDSCO. As far as the locally manufactured product is concerned, it has two-steps of approval: new drug approval granted by the National Authority (CDSCO) and manufacturing license, which is granted by the State Authority (state FDA) [73].
In India, a new drug is defined as any molecule or a combination of the existing molecules that's been used for the first time in the local market. Biologicals and biosimilars are always considered new drugs $[74,75]$.

The biosimilar regulatory guidelines were issued in September 2012, by CDSCO and Department of Biotechnology (DBT), with the help of industrial inputs and subsequently implemented. The major scope is to regulate the pathways for products claiming to be similar to an already authorized reference product [73]. All products obtained through modern biotechnological methods such as recombinant DNA technology are considered biological drugs [73].

Biosimilars are referred in India as similar biologics, i.e., "a biological product produced by genetic engineering techniques and claimed to be similar in terms of safety, efficacy and quality to the reference biologic, which has been granted a marketing authorization in India by DCGI on the basis of a complete dossier and with a history of safe use in India". If the reference product is not registered in India, drugs registered abroad could be taken into consideration as a reference if it has been licensed and marketed for at least four years, with significant efficacy and safety data. The reference product should be an innovator and must have full quality, efficacy and safety data. The same reference product, dose, strength, and route of administration should be used in all comparative studies. Details about the manufacturing should be as much thorough as possible: i.e., cell cultures, vectors, gene sequences and protein purification, to ensure the reproducibility of the manufacturing [73].

Biosimilars need to be comparable at quality (head to head comparison for stability, characterization and specification), preclinical (PD studies in vitro and in vivo, toxicity and immunogenic studies in animals) and clinical (single dose or multidose PK, PD, efficacy, safety and immunogenicity data recording) levels to the reference product.

As for other Countries, some products can be waived from the clinical studies if they meet the following conditions: they demonstrate structural and functional comparability to a high degree of confidence in physicochemical and in vitro studies, PK/PD studies, preclinical studies, and also if they have a comprehensive post-marketing risk management plan covering a Pharmacovigilance Plan, i.e., submission of PSURs ( 6 monthly for first 2 years, annually for next 2 years), adverse drug reaction reporting and post marketing studies [76].

Guidelines give information also on data archiving: data should be archived for 5 years of marketing approval. The site and the designated Authority to archive data should be indicated in protocols and reports. These guidelines do not provide any guidance for the substitution or interchangeability or on the nomenclature of biosimilars $[73,74]$.

Though all these indications are very robust, in Indian market there are biosimilars which haven't undergone these guidelines. The reason is that these guidelines came in effect only in September 2012, while biosimilars came to the market nearly a decade before. India has accepted the concept of 'similar biologics' since 2000, by approving it's first 'similar biologic' for a hepatitis B vaccine. In recent years, over 50 biopharmaceutical products have been approved for marketing in India, including monoclonal antibodies, EPO, etanercept, filgrastim, follicle stimulating hormones, insulins, interferons and streptokinases, with more than half of them being biosimilars [76,77] (supplementary Table 2).

Singapore: The Health Sciences Authority (HSA) of the Ministry of Health of the Singapore Government is responsible for overseeing 
all drug manufacturing, trade, and registration in Singapore to ensure the quality, safety and efficacy.

In August 2009, "Guidance on registration of similar biological products in Singapore" was published by the HSA, that, later in April 2011, was implemented by the Appendix 17 [78] and revisions to these guidelines were made in March 2012 [79,80].

In these guidelines, a biosimilar is defined as "a biological medicinal product referring to an existing registered product, submitted for medicinal product registration by an independent applicant, and is subject to all applicable data protection periods and/or intellectual property rights for the original product". As for many Countries, the reference product must be registered in Singapore and the same product should be used in all the comparability assessment for quality, safety and efficacy, in order to generate coherent data and conclusions. The active substance of a biosimilar must be similar, in molecular and biological terms, to the active substance of the reference product, as well as the pharmaceutical form, strength, and route of administration. Otherwise, additional data in the context of the comparability exercise should be provided. Any difference between the biosimilar and the reference product needs to be justified by appropriate studies on a caseby-case basis. Lastly, a warning statement on the risks associated with product switching during treatment and against product substitution, is to be included in the package insert of the biosimilar.

Saudi Arabia: The Saudi Food and Drug Authority (SFDA), responsible for overseeing all drug manufacturing, trade, and registration in Saudi Arabia, on $12^{\text {th }}$ December 2010 published the final guidelines covering biosimilars. The guideline, based on FDA and EMA documents, is entitled "Guidelines on biosimilars version 1.1" and it contains separate chapters on specific biosimilars, including insulin, interferon, EPO, G-CSF and growth hormones [81]

The reference product is defined as a biotechnology product produced by a multinational innovator and approved by FDA or EMA [82].

\section{South America}

Although many of the regulations for biosimilars in Latin America are based on guidelines from around the world, they vary widely among different Countries, especially for preclinical and clinical studies needed for comparability with a reference product or for the extrapolation. Also, the decision to choose which guideline is a free choice of each National Regulatory Authority.

As observed for other Countries, some biosimilars have been licensed prior to appropriate guideline being approved, for example, etanercept biosimilar in Colombia and rituximab biosimilar in Bolivia, Chile, Peru and Mexico [83]. An overview of regulatory activities for biosimilars is listed in Table 3 .

Most of the biological products are expensive and can't be afforded by the population living in poor regions such as Latin America. So, these markets have enormous potential for biosimilars, because it may help Governments to reduce the costs of biological products, the physicians would have more tools to combat diseases and patients would get increased access to modern therapies. Some Countries have made progress in this field by sanctioning the regulations for the biosimilars, but the Region as a whole remains under-prepared [84]. The common issue with guidelines in the Region is that regulatory bodies across Countries require different levels of evidence for the approval of biosimilars. Therefore, well-defined guidelines for the approval and pharmacovigilance of biosimilars as well as the pathway to harmonize regulations are still needed in Latin America. Though it is quite a demanding task, Pan American Network for Drug Regulatory Harmonization (PANDRH) has took this as its objective since 2010 and recommended that the Region should follow WHO guidelines [85]. Moreover, the governing bodies should also indicate the specific regulations for biosimilars without leaving any space for vague interpretations. To date biosimilars approved in Latin American market are infliximab, rituximab, and etanercept (Supplementary Table 3).

Brazil: The regulatory body for approval of medicines in Brazil is the Brazilian Health Surveillance Agency (Agência Nacional de Vigilância Sanitária, ANVISA), under the authority of the Ministry of Health, Mínistério de Saúde, of the Brazilian Government, for drug registration, licensing, clinical trials and drug pricing, together with the Chamber of Drug Market Regulation.

The first guidelines for biological products were published in 2002 , which included the same pathway for biosimilars, called follow on biologics, as that for the new biological drugs. Guidelines were revised in 2005 , with no change in regulations for the biosimilars, for which a full dossier is still required [86].

However, on $16^{\text {th }}$ December 2010, Brazil has issued guidelines for biosimilars based on the different regulations and documents all around the world, including Health Canada, EMA, KFDA, and WHO, although it mainly follows WHO Similar Biological Product Guidelines [87]. The similarities are regarding the use of a reference product based on a suitable period of market use and the demonstration of sufficient scientific information on quality, efficacy and safety, as well as the need for specific pharmacovigilance. The reference product could be a new biological product registered by another Regulatory Authority that adopts technical-scientific criteria similar to ANVISA's criteria (i.e., US, EU, CAN, AUS or JAP), with the possibility of full and unrestricted access to the registration information. The main difference is that the guideline provides two potential regulatory pathways for biosimilars: a comparative pathway and an individual development pathway.

In the comparative pathway, applicants are required to compare their biosimilar to the reference product, by supplying information regarding the origin of cells used in the production method, production process, quality parameters, and non-clinical/clinical studies. This route enables extrapolation of therapeutic indications and was adapted from the FDA Guidelines.

In the individual development pathway, the applicant needs to present complete data regarding quality issues, non-clinical and clinical phase I/II studies, but it does not have to be comparative. Nevertheless, both pathways require the submission of an immunogenicity study report and also the submission of pharmacovigilance and risk management plans for granting marketing authorizations $[40,88,89]$. Currently, there is one biosimilar, a low molecular weight heparin, approved under the individual development pathway.

A large number of biosimilars are approved by ANVISA, which includes: rituximab, golimumab, certolizumab, abatacept, tocilizumab, infliximab, adalimumab and etanercept. Moreover, to reduce the costs and shortage of drugs in the Brazilian market, in 2013, 27 public and private laboratories were engaged in a partnership (called Partnerships for Productive Development- PDP's) for the domestic production of 14 biosimilars Table 4 [90].

Argentina: The Administración Nacional de Medicamentos, 
Citation: Kumar R, Sigala S, Malgarini RB, Pimpinella G, Pani L, et al. (2015) Biosimilars: Regulatory Status and Implications across the World. J Pharmacovigilance S3: 002. doi:10.4172/2329-6887.S3-002

Page 10 of 14

\begin{tabular}{|c|c|c|c|c|}
\hline Country & Name for biosimilars & Regulatory authority & Relevant law & Year \\
\hline Argentina & Medicamento biológico similar & ANMAT & Legislation numbers 7075 and 7729 & 2008 \\
\hline Brazil & Follow-on biological products & ANVISA & Resolution no. 55/2010 & 2010 \\
\hline Chile & $\begin{array}{c}\text { Biosimilares } \\
\text { (biosimilar) }\end{array}$ & $\begin{array}{l}\text { Agencia Nacional de Medicamentos } \\
\text { (ANAMED) }\end{array}$ & $\begin{array}{l}\text { Regulations of the National System for the Control } \\
\text { of Pharmaceutical Products for Human Use D.S. } \\
\text { 3/2010 }\end{array}$ & 2011 \\
\hline Colombia & $\begin{array}{l}\text { Medication of successor } \\
\text { biological origin }\end{array}$ & $\begin{array}{l}\text { Instituto Nacional de Vigilancia de } \\
\text { Medicamentos y Alimentos(INVIMA) }\end{array}$ & Ministerial Decree 677/1995 & 2013 \\
\hline Costa Rica & Biosimilar medication & Ministerio de Salud & Decree no. 37006 & 2012 \\
\hline Cuba & Known biological product & $\begin{array}{c}\text { Centro para el Control Estatal de } \\
\text { Medicamentos, Equipos y Dispositivos } \\
\text { Médicos(CECMED) }\end{array}$ & Resolution no. 56/2011 & 2011 \\
\hline Guatemala & Biosimilar biocomparable & $\begin{array}{l}\text { Ministerio de Salud Pública y Asistencia } \\
\text { Social }\end{array}$ & Technical standard 67-2010 & 2010 \\
\hline Mexico & $\begin{array}{l}\text { Biocomparables } \\
\text { (biocomparable) } \\
\text { Biotechnological medicine }\end{array}$ & COFEPRIS & $\begin{array}{l}\text { Article } 222 \text { bis in the Mexican Health Law (Articule } \\
39 \text { de la Ley Orgánica de la Administración Pública } \\
\text { Federal y } 222 \text { Bis de la Ley General de Salud) }\end{array}$ & 2012 \\
\hline Panama & Notstated & Ministerio de Salud Panama (MINSA) & Executive Decree no. 340 & 2007 \\
\hline Peru & $\begin{array}{l}\text { Producto biológico } \\
\text { similar(similar biological } \\
\text { product) }\end{array}$ & Ministerio de Salud Peru (MINSA) & Supreme Decree no. 016-2011-SA & 2012 \\
\hline
\end{tabular}

Based on [80]

Table 3: Biosimilar regulations in Latin America.

\begin{tabular}{|c|c|c|c|}
\hline Indication & Reference Product & Public partners & Private partners \\
\hline \multirow{4}{*}{ Rheumatoid Arthritis } & Adalimumab & Bio-Manguinhos, IVB, Bahiafarma & Orygen, Alteogen, PharmaPraxis, Libbs, Mabxience \\
\hline & Cerolizumab & Bio-Manguinhos & UCB Pharma, Meizler \\
\hline & Etanercept & IVB, Bio-Manguinhos, Butantan, Bahiafarma & Bionovis, Libbs, Mabxience, Orygen, Alteogen \\
\hline & Infliximab & IVB, Bio-Manguinhos & Bionovis \\
\hline Immunotherapy & Vaccine & Bahiafarma & Biocen, Salundinvest \\
\hline $\begin{array}{l}\text { Oncology/age-related } \\
\text { macular degeneration }\end{array}$ & Bevacizumab & Tecpar, Butantan, Bio-Manguinhos, IVB & Biocad, Libbs, Mabxience, Orygen, Alteogen, Bionovis \\
\hline \multirow[t]{4}{*}{ Oncology } & Cetuximab & IVB, Bio-Manguinhos, Butantan & Bionovis, Libbs, Mabxience \\
\hline & Trastuzumab & Bahiafarma, Bio-Manguinhos, IVB & Libbs, Mabxience, Orygen, Alteogen, PharmaPraxis \\
\hline & L-asparaginase & Fiocruz & NT Pharma, UnitedBiotec \\
\hline & Filgrastim & Bio-Manguinhos & Eurofarma \\
\hline Cicatrizant & Fibrine & Hemobrás, IBMP & Cristália \\
\hline Diabetes & Insulin & Farmanguinhos & Biomm, Indar \\
\hline Growthhormone & Somatropin & Bio-Manguinhos, Funed & Cristália, Pfizer \\
\hline
\end{tabular}

Source: IHS.

Table 4: Biologicals to be produced through PDP's

Alimentos y Tecnología Médica (National Administration of Drugs, Foods and Medical Devices; ANMAT) is responsible for the quality, authorization, registration, standardization, vigilance and monitoring of drugs used in the human medicine, foodstuff, medicinal products, diagnosis reagents, cosmetic products, dietary supplements and household cleaning products in Argentina.

In July 2008, ANMAT issued a draft guideline for biosimilars, or medicamento biológico similar entitled "Registration and registry modification of biological medicinal products". This guideline, based on the EMA guidelines, allows for an abbreviated licensing pathway for biosimilars. Furthermore, it defines as biosimilar, a medicinal product that is similar in terms of quality, safety, and efficacy to a reference product, which has already been authorized by the Health Authority [40,91].

Peru: The Authority responsible for the registration, control and sanitary surveillance of pharmaceutical products, the Ministry of Public Health (Ministerio de Salud; MINSA), published guidelines for biosimilars (productos biológicos similares) on $31^{\text {st }}$ July 2011, which came into effect on $9^{\text {th }}$ November 2012, in a document entitled
"Regulation for the registration, control and pharmacovigilance of pharmaceutical products, medical devices and sanitarian products Decree N-016-2011-SA" [92].

Though, these guidelines do not define what a biosimilar is, but they do allow for an abbreviated licensing pathway for biosimilars based on the WHO guidelines. There is one more complementary document, which gives more specific requirements for the biologicals and biosimilars entitled "Health Directive governing the presentation and content of the documents required in the registration and reregistration of biological products: Biotechnology", which came into effect on $20^{\text {th }}$ February 2013 [93].

Colombia: The Colombian Ministry of Health and Social Protection (Ministerio de Salud y Protección Social de Colombia) issued draft guidance for biological, including productos bioterapéuticos similares (biosimilars) on $21^{\text {st }}$ January 2013, based on FDA guidelines. This draft provides three pathways for biological products: a complete pathway, a comparability pathway and an abbreviated pathway, the latter aiming to facilitate the registration of biosimilars [40,94].

Venezuela: The Instituto Nacional de Higiene 'Rafael Rangel 
(INHRR National 'Rafael Rangel’ Institute of Hygiene) released a draft guideline for bioterapéuticos similares (similar biotherapeutics), through its National Monitoring Biological Products Division on $12^{\text {th }}$ June 2012. It defines biosimilars as "biotechnology-derived drugs that are similar in terms of quality, safety and efficacy to their reference biotherapeutic products". The draft guideline facilitates the registration of biosimilars in Venezuela, through an abbreviated pathway in its document entitled "Norma para registro sanitario y farmacovigilancia de productos bioterapéuticos similares en la República Bolivariana de Venezuela". Moreover, it covers well-defined and characterized biotechnology products, i.e. drugs whose active ingredient are therapeutic proteins derived from recombinant DNA or monoclonal antibodies, but doesn't include vaccines, plasma products or other biological products whose preparation does not involve genetic manipulation. According to the draft guideline, extrapolation of indications is not allowed $[40,95]$.

\section{Africa}

South Africa: The Medicine Control Council (MCC) of Department of Health of Republic of South Africa $2^{\text {nd }}$ May 2012 issued final guidelines for biosimilars that follow the EMA guidelines. Guidelines outline the quality, non-clinical and clinical requirements for biosimilars. The quality section addresses the physico-chemical structural and functional requirements. The non-clinical section addresses pharmaco-toxicological assessments. The clinical section addresses requirements for PK, PD, efficacy and safety studies, with special emphasis on studying the immunogenicity of biosimilars [96]. Guidelines refer to biosimilar as "synonymous with follow-on biologics and similar biotherapeutic products (SBP). A biosimilar is a biological medicine that is similar, but not necessarily identical, in terms of quality, safety and efficacy to an already registered reference biological medicine". The reference product is defined as "the innovator product A medicine which has been licensed by a national regulatory authority which Council aligns itself with, on the basis of a full registration dossier; i.e. the approved indication(s) for use were granted on the basis of full quality, efficacy and safety data."

Egypt: The Egyptian Drug Authority (EDA), together with the Central Administration for Pharmaceutical Affairs (CAPA) and the National Organization for Research and Control of Biologics (NORCB), issued draft guidelines for the registration of biosimilars on 20 January 2013, which were effective from $2^{\text {th }}$ September 2014, entitled Guidelines for Registration of Biosimilar Products in Egypt [97,98]. Earlier, the Ministerial Decree 297/2009 demanded a full dossier regarding quality, preclinical and clinical data for the registration of a biosimilar, but the new guidelines allowed an abbreviated pathway. Current documents are based on the EMA, ICH, WHO, FDA and Indian guidelines for biosimilars.

Biosimilar in Egypt is described as "biological product (other than blood-derived products their recombinant analogues, vaccines and sera) having the same active substance, dosage form, concentration and route of administration [as that] of a reference biological product and [having been] proven through a comparability program [me] that its quality, safety and efficacy is equivalent to a reference product when prescribed in a claimed indication". Furthermore, it states that biosimilars are "officially-approved similar versions of innovator biopharmaceutical products made by a different sponsor" [98].

The Egyptian Authorities allow two approaches for the registration of biosimilars: stand-alone approach (complete product development program regarding quality, preclinical and clinical studies) or biosimilar approach, in which the applicant needs to perform a complete product CMC development process, comparability quality exercise, and preclinical and clinical comparability studies (which can be reduced), in order to demonstrate the biosimilarity of the proposed biological product to a reference product.

\section{Oceania}

Australia: The Therapeutics Goods Administration (TGA), Australia's Regulatory Agency, issued the guidance for biosimilars on $1^{\text {st }}$ July 2013, entitled Evaluation of Biosimilars, based mainly on EMA guidelines. According to TGA, this guidance is for assisting sponsors to identify data necessary to support applications and clarify the scientific and regulatory principles for biosimilar registration in Australia. Though, this guidance is only for biosimilars containing biotechnology derived proteins as active substances, but it also applies to more complex biosimilars, such as vaccines and monoclonal antibodies, or polysaccharides as heparins.

It refers to biosimilar as a similar biological medicinal product (SBMP) which is "a version of an already registered medicine (reference product). The SBMP should have a demonstrable similarity in physiochemical, biological and immunological characteristics, efficacy and safety that should be based on comprehensive comparability studies". This guidance also includes the robust criteria for the reference products, naming conventions of the biosimilars, post registration regulations, a pharmacovigilance plan and labeling and product information to ensure the biosimilar efficacy and safety.

Moreover, the reference product should be clearly identified by brand name, pharmaceutical form, formulation, strength, origin or place of purchase, batch number and dates of expiry. Also, as for the Regulatory Agencies in many other Countries, it should have been marketed for a suitable time duration and have a volume of marketed use to have substantial data regarding efficacy and safety. A biosimilar itself cannot be a reference product. If the reference product is manufactured overseas, then it should have been registered in Australia and a bridging comparability study between the Australiansourced product and all batches of the reference product should be provided. Sponsors are encouraged to demonstrate the similarity between biosimilar and its reference product according to the EMA guidelines regarding the significant manufacturing process changes or the extrapolation of indications [99].

Furthermore, the mandatory post-registration plan for pharmacovigilance requires that the sponsor notify to the TGA a person responsible for fulfilling any request from TGA for the provision of additional information answered within the requested timeframe, submit Periodic Safety Update Reports (PSURs) and adverse events.

The biosimilar naming conventions should imply the Australian Biological Names, which is stated in the Therapeutics Goods Regulations (1990) (i.e., all medicines are required to use the Australian Approved Names (AAN). Biosimilars should follow the WHO guidelines on the biosimilar identifier, thus giving the WHO International NonProprietary Name (INN). Moreover, Therapeutics Goods Order no.69 gives the general requirements for medicine labels that should contain all active ingredients and excipients. The TGA sustains that the trade names for biosimilars should be different from the reference product and other biosimilars, in order to not confuse them with generics.

These guidelines underwent review by TGA in April 2015, as they state that knowledge on biosimilars is ever evolving. The major change, according to TGA, in these new guidelines will be in the area of biosimilar naming. This is due to the fact that, in July 2014, the WHO - 
INN published a draft policy "Biological Qualifier- an INN Proposal", which superseded the previous INN position on which the TGA policy was based [100].

Since 2010, 9 biosimilars of EPO, filgrastim, insulins and somatropin have been approved by TGA, (Supplementary Table 4).

New Zealand: The New Zealand Medicines and Medical Devices Safety Authority (Medsafe) is the regulatory body for approval of medicines in New Zealand, which ensures for the medicines and medical devices to be acceptably safe in the country. Medsafe does not cite any specific New Zealand guidelines for biosimilars, but it refers to both the US and EMA guidelines. It also states that approval of a biosimilar is based on non-clinical studies (PK and PD studies) as well as comparative human clinical studies, that should not show any important differences between the biosimilar and the reference product in terms of efficacy and safety [101]. The package insert should contain the statement that the product is a biosimilar, if the product is known to be non-interchangeable and also the reference to the Medsafe webpage for further information on biosimilars. A statement regarding the decision for interchangeability should involve the prescribing physician and the information from clinical studies for comparability of the reference product should also be included in the package insert.

Medsafe defines a biosimilar as "a new biological product that is similar to another biological medicine that has been granted consent to be marketed in New Zealand (the biological reference)". Applications to distribute drugs described as biosimilars need to be accompanied by data according to annexes to the CHMP Guideline (EMA) on similar biological medicinal products containing biotechnology-derived proteins as active substance: non-clinical and clinical issues. These applications must also include any additional data as required by the Medicines Act 1981 and the NZRGM (New Zealand Regulatory Guide for Medicines) and a risk management plan covering the introduction of the product in New Zealand [101,102].

Since 2012, 7 biosimilars were approved by Medsafe including EPO, filgrastim, rituximab, somatropin and trastuzumab (Supplementary Table 4).

\section{Conclusion}

Biosimilars are essential pharmaceutical products that could make important biological drugs available to different markets at an affordable cost. The expiry of patent protection of many biological drugs led to the need for specific guidance regarding the development and approval of biosimilars.

Many regulatory systems take a different approach between biosimilars and generics, because the bioequivalence for a biosimilar product cannot be easily established [17]. This is due to their structural complexity, the use of living organisms for manufacturing processes, difficulties in achieving consistency of manufactured batches and sometimes complex long term effects of their patient administration.

Though most of the Regulatory Authorities opted for an abbreviated pathway for a biosimilar approval, bringing biosimilars to the market is still a challenging task. As it still requires large investments of money, fewer biosimilars are expected to enter the biologic market compared to what happened with generic market after the Hatch Waxman Act in 1984 [33,103]. Additionally, due to the high regulatory hurdles for the interchangeability and comparability with the reference product, biosimilars have to compete with their reference products not as therapeutic equivalents but as therapeutic alternatives. Nevertheless, the biosimilar use is ought to increase in the coming times as per the demand and supply of these drugs is concerned.

We believe that the biosimilar costs will be reduced in the future, if the harmonization of international comparability trials will succeed. This could be further improved if Countries will let the pharmaceutical companies to compare biosimilars at the international stage with the reference product, which may not necessarily being authorized by the given Country and permitting the extrapolation (under keen observation) of other indications for which a reference product has been approved. This observation may not exempt the pharmaceutical company to ensure a robust and impeccable comparability between a biosimilar and its originator. In conclusions, to achieve a balance between drug quality and safety and the population health needs, it's of fundamental importance to have a profound knowledge of biosimilar development, as well as joint effort of all biosimilar manufacturers to come together for decreasing the costs of production by sharing some of the manufacturing steps with each other's [104].

\section{References}

1. Avidor $\mathrm{Y}$, Mabjeesh NJ, Matzkin $\mathrm{H}$ (2003) Biotechnology and drug discovery: From bench to bedside. South Med J 96: 1174-1186.

2. Dranitsaris G, Amir E, Dorward K (2011) Biosimilars of biological drug therapies: Regulatory, clinical and commercial considerations. Drugs 71: 1527-1536.

3. Crommelin DJ, Storm G, Verrijk R, de Leede L, Jiskoot W, et al. (2003) Shifting paradigms: Biopharmaceuticals versus low molecular weight drugs. Int $J$ Pharm 266: 3-16.

4. Brockmeyer C, Seidl A (2009) Binocrit: assessment of quality, safety and efficacy of biopharmaceuticals. Ejhp Practice 15: 34-40.

5. Schellekens $\mathrm{H}(2004)$ When biotech proteins go off-patent. Trends Biotechnol 22: $406-410$

6. Rathore N, Rajan RS (2008) Current perspectives on stability of protein drug products during formulation, fills and finishes operations. Biotechnol Prog 24 504-514.

7. Höglund M (1998) Glycosylated and non-glycosylated recombinant human granulocyte colony-stimulating factor (rhG-CSF)--what is the difference? Med Oncol 15: 229-233.

8. Hooker A, James D (1998) The glycosylation heterogeneity of recombinan human IFN-gamma. J Interferon Cytokine Res 18: 287-295.

9. Locatelli F, Del Vecchio L, Pozzoni P (2007) Pure red-cell aplasia "epidemic"-mystery completely revealed? Perit Dial Int 27 Suppl 2: S303-307.

10. Schellekens H (2004) How similar do 'biosimilars' need to be? Nat Biotechnol 22: $1357-1359$

11. Keithi-Reddy SR, Kandasamy S, Singh AK (2008) Pure red cell aplasia due to follow-on epoetin. Kidney Int 74: 1617-1622.

12. Yang J, Joo KW, Kim YS, Ahn C, Han JS, et al. (2005) Two cases of pure redcell aplasia due to anti-erythropoietin antibodies. J Nephrol 18: 102-105.

13. Crommelin D, Bermejo T, Bissig M, Damiaans J, Krämer I, et al. (2005) Biosimilars, generic versions of the first generation of therapeutic proteins: do they exist? Contrib Nephrol 149: 287-294.

14. Seidl A, Hainzl O, Richter M, Fischer R, Böhm S, et al. (2012) Tungsten-Induced Denaturation and Aggregation of Epoetin Alfa During Primary Packaging as a Cause of Immunogenicity. Pharm Res 29: 1454-1467.

15. Pani L, Montilla S, Pimpinella G, Bertini Malgarini R (2013) Biosimilars: The paradox of sharing the same pharmacological action without full chemical identity. Expert Opin Biol Ther 13: 1343-1346.

16. Lewis RM, Cosenza ME (2010) Summary of DIA Workshop: Comparability Challenges: Regulatory and Scientific Issues in the Assessment of Biopharmaceuticals. Drug Information Journal 44: 485-504

17. Putnam WS, Prabhu S, Zheng Y, Subramanyam M, Wang YM (2010) Pharmacokinetic, pharmacodynamic and immunogenicity comparability assessment strategies for monoclonal antibodies. Trends Biotechnol 28: 509- 
Citation: Kumar R, Sigala S, Malgarini RB, Pimpinella G, Pani L, et al. (2015) Biosimilars: Regulatory Status and Implications across the World. J Pharmacovigilance S3: 002. doi:10.4172/2329-6887.S3-002

516

18. Kessler M, Goldsmith D, Schellekens H (2006) Immunogenicity of biopharmaceuticals. Nephrol Dial Transplant 21 Suppl 5: v9-v12.

19. Porter S (2001) Human immune response to recombinant human proteins. J Pharm Sci 90: 1-11.

20. Ryff JC, Schellekens H (2002) Immunogenicity of rDNA-derived pharmaceuticals. Trends Pharmacol Sci 23: 254-256.

21. Schellekens $H(2005)$ Immunologic mechanisms of EPO-associated pure red cell aplasia. Best Pract Res Clin Haematol 18: 473-480.

22. Schellekens $H(2005)$ Factors influencing the immunogenicity of therapeutic proteins. Nephrol Dial Transplant 20 Suppl 6: vi3-9.

23. Schellekens $\mathrm{H}$ (2005) Follow-on biologics: Challenges of the "next generation". Nephrol Dial Transplant 20 Suppl 4: iv31-36.

24. Locatelli F, Roger S (2006) Comparative testing and pharmacovigilance of biosimilars. Nephrol Dial Transplant 21 Suppl 5: v13-v16.

25. World Health Organization. Trade, foreign policy, diplomacy and health Generic Drugs

26. Vanrenterghem Y, Bárány P, Mann JF, Kerr PG, Wilson J, et al. (2002) Randomized trial of darbepoetin alfa for treatment of renal anemia at a reduced dose frequency compared with rHuEPO in dialysis patients. Kidney Int 62 2167-2175.

27. Dellanna F, Winkler RE, Bozkurt F, Schettler V, Graf S, et al. (2011) Dosing strategies for conversion of haemodialysis patients from short-acting erythropoiesis stimulating agents to once-monthly C.E.R.A.: Experience from the MIRACEL study. Int J Clin Pract 65: 64-72.

28. Ebbers HC, Muenzberg M, Schellekens H (2012) The safety of switching between therapeutic proteins. Expert Opin Biol Ther 12: 1473-1485.

29. Weise M, Bielsky MC, Smet KD, Ehmann F, Ekman N, et al. (2011) Biosimilarswhy terminology matters. Nat Biotechnol 29: 690-693.

30. World Health Organization (2013) International Nonproprietary Names (INN) for biological and biotechnological substances.

31. Food and Drug Administration (2015) Scientific Considerations in Demonstrating Biosimilarity to a Reference Product: Guidance for Industry.

32. Declerck PJ (2012) Biologicals and biosimilars: A review of the science and its implications. Generics and Biosimilars Initiative Journal Journal 1: 4

33. Blackstone EA, Joseph PF (2013) The economics of biosimilars. Am Health Drug Benefits 6: 469-478.

34. Amgen Inc (2014) Biologics and biosimilars: An overview.

35. European Medicines Agency (2005) Guideline on similar biological medicinal products.

36. European Medicines Agency (2014) News: Facilitating global development of biosimilars.

37. European Medicines Agency (2014) Guideline on similar biological medicinal products containing biotechnology-derived proteins as active substance: quality issues (revision 1)

38. European Medicines Agency (2014) Guideline on similar biological medicinal products containing biotechnology-derived proteins as active substance: nonclinical and clinical issues.

39. Ivmueller (2014) An Overview of Biosimilars in the Russian Federation.

40. Castañeda-Hernández G, Szekanecz Z, Mysler E, Azevedo VF, Guzman R, et al. (2014) Biopharmaceuticals for rheumatic diseases in Latin America, Europe, Russia, and India: Innovators, biosimilars, and intended copies. Joint Bone Spine 81: 471-477.

41. Elena M (2013) Development vector of regulatory procedures of biological medicines in Russia.

42. FDA (2014). Guidance for Industry: Reference Product Exclusivity for Biological Products Filed Under Section 351(a) of the PHS Act. August 2014 procedural.

43. FDA (2009) Title VII-Improving access to innovative medical therapies. Subtitle A-Biologics Price Competition and Innovation.

44. Democrats senate govt (2010) The patient protection and affordable care act.
45. Food and Drug Administration (2015) Quality Considerations in Demonstrating Biosimilarity of a Therapeutic Protein Product to a Reference Product: Guidance for Industry. Biosimilarity.

46. Food and Drug Administration (2015) Biosimilars: Questions and Answers Regarding Implementation of the Biologics Price Competition and Innovation Act of 2009: Guidance for Industry.

47. Food and Drug Administration (2015). Biosimilars.

48. Food and Drug Administration (2011) Implementation of the Biologics Price Competition and Innovation Act of 2009

49. Food and Drug Administration (2014) Guidance for Industry: Clinica Pharmacology Data to Support a Demonstration of Biosimilarity to a Reference Product.

50. Food and Drug Administration (2013) Guidance for Industry: Formal Meetings Between the FDA and Biosimilar Biological Product Sponsors or Applicants.

51. Food and Drug Administration (2014) Guidance for Industry: Reference Product Exclusivity for Biological Products Filed Under Section 351(a) of the PHS Act.

52. Food and Drug Administration (2015) FDA approves first biosimilar product Zarxio.

53. Generics and Biosimilars Initiative Journal Journal (2015) FDA approves its first biosimilar

54. Health Canada (2011) Guidance Document: Data Protection under C.08.004.1 of the Food and Drug Regulations.

55. Health Canada (2015) Guidance Document: Patented Medicines (Notice of Compliance) Regulations.

56. Health Canada (2010) Questions and Answers To Accompany the Final Guidance for Sponsors: Information and Submission Requirements fo Subsequent Entry Biologics (SEBs).

57. Health Canada (2015) Guidance For Sponsors: Information and Submission Requirements for Subsequent Entry Biologics (SEBs).

58. Agnes VK, Bedford P, Wang J (2014) Subsequent entry biologics (biosimilars) in Canada: Approaches to interchangeability and the extrapolation of indications and uses. Generics and Biosimilars Initiative Journal Journal 3: 150-154.

59. Ibarra-Cabrera R, Mena-Pérez SC, Bondani-Guasti A, García-Arrazola R (2013) Review on the worldwide regulatory framework for biosimilars focusing on the Mexican case as an emerging market in Latin America. Biotechnol Adv 31: $1333-1343$

60. Diario Oficial de la Federación (2011) Decree which amends and adds various provisions of the regulation of health supplies.

61. Generics and Biosimilars Initiative Journal Journal (2012) Mexican guidelines for biocomparables.

62. PMDA (2013) Guideline for the Quality, Safety, and Efficacy Assurance of Follow-on Biologics.

63. KFDA (2009) Evaluation Guidelines for Biosimilars.

64. Generics and Biosimilars Initiative Journal Journal (2014) Biosimilars approved in South Korea.

65. Drug Regualtions (2014) China's Biosimilar Guidance.

66. China Drug Consulting (2015) China Releases Biosimilar Guidelines.

67. Ropes and Gray (2015) China Announces Final Biosimilars Guideline

68. Covington (2014) China releases proposed guidance on the development of similar biotherapeutic products.

69. Bird and bird (2015) China: CFDA drafts guidelines for biosimilars

70. Generics and Biosimilars Initiative Journal Journal (2014). Chinese guidelines for biosimilars.

71. Innovent Biologics (2014) Change of Biosimilars in China by Reuters.

72. Ivmueller (2014) An overview of biosimilars and the biosimilar pathway in India.

73. Rathore A (2012) Guidelines on similar biologics: Regulatory requirements for marketing authorization in India. PDA J Pharm Sci Technol 66: 393.

74. Kumar R, Singh J (2014) Biosimilar drugs: Current status. Int J Appl Basic Med Res 4: 63-66. 
Citation: Kumar R, Sigala S, Malgarini RB, Pimpinella G, Pani L, et al. (2015) Biosimilars: Regulatory Status and Implications across the World. J Pharmacovigilance S3: 002. doi:10.4172/2329-6887.S3-002

Page 14 of 14

75. Garima S (2015) New drug approval procedure in India

76. Joshi SR (2011) Biosimilar peptides: need for pharmacovigilance. J Assoc Physicians India 59 Suppl: 44-47.

77. Kumar R, Singh J (2014) Biosimilar drugs: Current status. Int J Appl Basic Med Res 4: 63-66.

78. Poh J, Tam KT (2011) Registration of similar biological products--Singapore's approach. Biologicals 39: 343-345.

79. HSA (2011) Updates to guidance on medicinal product registration in Singapore.

80. Generics and Biosimilars Initiative Journal Journal (2012) Singapore guidelines for biosimilars.

81. Generics and Biosimilars Initiative Journal Journal (2011) Saudi Arabian guidelines for biosimilars.

82. Saudi Food and Drug Authority (2010) Drug Master File Requirements for the Registration of Biosimilars.

83. Generics and Biosimilars Initiative Journal Journal (2013) Regulation of similar biotherapeutic products in Latin America.

84. Generics and Biosimilars Initiative Journal (2014). Recommendations for the regulation of biosimilars and their implementation in Latin America.

85. PANDRH (2013) VII conference of the Pan American Network for Drug Regulatory Harmonization (CPANDRH).

86. Generics and Biosimilars Initiative Journal Journal (2012) Brazilian guidelines for follow-on biological products.

87. Chiann C, de Santana F, Cardoso S, da Costa César I, Pianetti GA (2013) Biosimilarity in Latin America. Generics and Biosimilars Initiative Journal Journal 2: 94-96.

88. Pharmaceutical executive editors (2014) Complex Drugs and Biologics: Policy Considerations in Brazil.

89. Tsuruta LR, Lopes Dos Santos M, Moro AM (2015) Biosimilars advancements: Moving on to the future. Biotechnol Prog.
90. IHS (2013) Brazil to expand local production of biologic drugs with 14 new products.

91. Generics and Biosimilars Initiative Journal Journal (2013) Argentinian guidelines for similar biological medicines.

92. Ministerio De Salud (2012) Modifican artículos del reglamento para el registro control y vigilancia sanitaria de productos farmacéuticos, dispositivos médicos y productos sanitarios.

93. Generics and Biosimilars Initiative Journal Journal (2014) Peruvian guidelines for productos biológicos similares.

94. Generics and Biosimilars Initiative Journal Journal (2013) Colombia issues draft decree for registration of biologicals.

95. Generics and Biosimilars Initiative Journal Journal (2013) Venezuela issues draft guideline for bioterapéuticos similares.

96. Medicines Control Council (2012) Biosimilar medicines: Quality, Non-clinical and Clinical requirements.

97. Ministry of Health (2014) Guidelines For Registration of Biosimilar Products In Egypt.

98. Generics and Biosimilars Initiative Journal Journal (2013) Egypt issues draft guidelines for biosimilars.

99. Therapeutic Goods Administration (2013) Evaluation of biosimilars.

100. Generics and Biosimilars Initiative Journal Journal (2014) Biosimilars approved in Australia.

101. Medsafe NZ (2014) Medsafe position on Biosimilar Medicines.

102. Medsafe NZ (2014) Medicines Biosimilars.

103. Amanda B (2015) The Hatch-Waxman Act.

104. Senate and house of Representatives of the United States of America.
This article was originally published in a special issue, entitled: Biosimilars Pharmacovigilance and Risk Management, Edited by Eugenia Yiannakopoulou, Faculty of Health and Caring Professions, Technological Educational Institute of Athens, Greece 